\section{PAP over poppies}

\section{By Michael J. Haas, Senior Writer}

A team of researchers from Finland and the U.S. has shown that prostatic acid phosphatase-a protein once used as a biomarker for prostate cancer-could be a better therapeutic agent than morphine for treating central neuropathic and chronic inflammatory pain. To harness the fullest therapeutic potential of prostatic acid phosphatase, researchers suggest developing a small molecule mimetic.

Central neuropathic pain occurs in spinal cord injury, multiple sclerosis (MS), some strokes and possibly fibromyalgia (FMA), for which neuropathic pain therapies are sometimes effective. Therapeutics to treat neuropathic pain are taken over long periods, thus making safety a key focus. Indeed, although morphine is one of the most effective agents, side effects limit its use. Nonopioid therapeutics for neuropathic pain deliver at best only partial relief in most patients.

In a paper published in Neuron, a team led by Mark Zylka and Pirkko Vihko report that prostatic acid phosphatase (PAP; ACPP) generates free adenosine in the neurons of mice to deliver pain relief that lasts longer than morphine without any apparent side effects. ${ }^{1}$

Zylka is an assistant professor of cell and molecular physiology at the University of North Carolina at Chapel Hill, and Vihko is a professor of biochemistry at the University of Helsinki. The team also included scientists from the University of Oulu.

PAP is secreted by the prostate. Although it is not thought to play a causal role in prostate cancer, high levels of the protein were used as a biomarker for prostate cancer from the 1940s until the 1980s, when prostate-specific antigen (PSA) replaced it as the biomarker of choice. Vihko has studied PAP for more than 30 years, and her work has included producing recombinant PAP, solving its 3D structure and understanding regulation of the PAP gene.

Last year, Vihko and colleagues discovered a transmembrane isoform of PAP. ${ }^{2}$ They found that-unlike the secreted isoform, which is expressed only in the prostate-transmembrane PAP is widely expressed in many human tissues and organs.

She told SciBX: "Now we have mice in which both forms are knocked out together."

Meanwhile, Zylka's group had been working to identify the gene that coded thiamine monophosphatase-also known as fluoride-resistant acid phosphatase-an enzyme found in pain-regulating neurons of the CNS. The results of their studies pointed to PAP as the gene that coded for thiamine monophosphate protein, but they needed a PAP knockout model to confirm their findings. Zylka's search for a model led him to Vihko, who provided neural tissue samples from her group's PAP-deficient mice.
That initial collaboration led to the joint study reported in Neuron.

The team's studies of the mouse neural tissue samples revealed that the transmembrane isoform of PAP was the same protein as thiamine monophosphatase and was expressed in sensory neurons called nociceptors, which stimulate pain in response to injury.

The group also showed that mice deficient in both forms of PAP were more sensitive to chronic inflammatory pain and central neuropathic pain than normal mice. But after receiving intraspinal injections of the secreted isoform of PAP, the mice exhibited pain sensitivity comparable to normal mice. That result suggested PAP itself could block pain.

In behavioral models of inflammatory and central neuropathic pain, the team found that PAP injected into normal mice delivered pain relief that lasted for days compared with relief lasting only a few hours for the same dose of morphine. Moreover, mice receiving PAP did not exhibit signs of sedation or, at higher doses, paralysis or death that similar doses of morphine can induce.

"The highest dose of morphine that did not cause these effects was about $1 \mu \mathrm{g}$," Zylka said. "The same dose of PAP was at least 8 times more effective than morphine-and maybe as much as 20 times more effective," he said.

Lastly, experiments in human embryonic kidney cells and neural tissue samples from both normal mice and mice deficient in both PAP isoforms showed that PAP dephosphorylates adenosine monophosphate (AMP) in neurons of the CNS to generate adenosine, which in turn activates adenosine $A_{1}$ receptors to block pain.

Zylka told SciBX that both PAP isoforms can dephosphorylate AMP.

\section{Gain with no pain}

Zylka said that PAP or PAP mimetics could be delivered therapeutically by pump to treat pain in the same manner as morphine and Prialt ziconotide, an N-type calcium channel blocker marketed by Elan Corp. plc. Prialt must be delivered by intrathecal (intraspinal) injection because it does not cross the blood-brain barrier.

Zylka added that PAP is not likely to lead to dependence or tolerance because it does not activate the reward centers of the brain as morphine and other opioids do.

Vihko agreed that the delivery of recombinant PAP via pump would be a good first step toward the therapeutic application of the team's findings. She noted that she and colleagues at the University of Oulu previously described a scale-up procedure for synthesizing large quantities of pure recombinant PAP. ${ }^{3}$ That should facilitate therapeutic development of the protein, she said.

"The possibility of introducing PAP in pain therapy is an extremely exciting possibility," said Bert Csillik, professor emeritus of neuroanatomy at Albert Szent-Györgyi University Medical School. "Until now we never suspected that an enzyme might be a better anti-nociceptive agent than opiates in the realm of primary sensory neurons."

Csillik and his wife, Elizabeth Knyihár-Csillik, a retired associate professor and scientific advisor of clinical neurology at Albert Szent-Györgyi, have studied thiamine monophosphatase for more than 30 years-ever since Knyihár discovered the enzyme’s role in nociceptive pain. ${ }^{4}$ 


\section{TARGETS \& MECHANISMS}

Yotam Nisemblat, drug development manager at BioLineRx Ltd., agreed that the Neuron study was a clear advance in the understanding of pain. "Although it is well established that adenosine receptors are involved in the mechanisms of pain, this is the first study to show the involvement of thiamine monophosphatase/PAP in this process and its potential as a treatment for pain," he said.

Nisemblat said PAP's advantages over morphine made it an attractive alternative to the opioid, especially if further studies show that PAP can be delivered intravenously or orally. "These kinds of studies could show if it penetrates into the spinal cord and also evaluate the systemic effects of the drug," he told SciBX.

He did say the side effects of systemic PAP were a concern because adenosine and its phosphates-cyclic adenosine monophosphate, adenosine diphosphate and ATP_are involved in many biological processes, such as energy transfer and signal transduction.

Other studies involving repeated administration of PAP should be run "to exclude the possibility of tolerance and in order to see the side effects of chronic treatment," Nisemblat said.

Rather than use PAP itself, Nisemblat thinks a small molecule PAP mimetic might be preferable in chronic pain indications, as it could be given orally and would cost less. He also suggested that a PAP fragment or a smaller peptide might overcome the difficulties associated with developing a large protein therapeutic.

Nisemblat manages the development of BioLineRx's BL-1021, an orally available ion channel blocker in preclinical development for neuropathic pain and for acute and chronic pain. The company plans to start Phase I trials in 2009.

Zylka acknowledged that systemic administration of PAP might have side effects, but did not think these would be serious. Although high doses of adenosine $\mathrm{A}_{1}$ receptor agonists can cause paralysis, "PAP is catalytically restricted-the amount of adenosine it can generate is limited by the amount of AMP present," he said. Thus Zylka argued that PAP probably cannot generate enough free adenosine to activate the adenosine $\mathrm{A}_{1}$ receptors and induce paralysis.

Zylka did note that adenosine is used to treat tachycardia (rapid heartbeat) and arrhythmia, so the use of PAP to treat pain could have the unwanted side effect of slowing the heartbeat.

David Urdal, CSO of Dendreon Corp., agreed that the side effects of systemic use of PAP were not likely to be serious. "I would not expect to see unusual effects since serum levels of PAP have been used to follow prostate cancer for decades and some patients have been reported to have high levels of circulating PAP," he said.

Urdal added: "It would be interesting to know if patients with high circulating PAP have less pain."
Dendreon's Provenge sipuleucel-T, an immunotherapy that targets PAP-expressing cells, is in a Phase III trial to treat androgen-independent prostate cancer (AIPC).

\section{More PAP tests}

Zylka said his group at UNC is seeking molecules that will either enhance the activity of PAP or act as PAP mimetics. "Our studies are preliminary, but proof-of-principle experiments suggest that small molecule PAP mimetics will work" to relieve neuropathic and inflammatory pain, he said.

His group is also studying how PAP functions at a mechanistic level in pain, but declined to disclose details about those studies. He added that he and his group have not yet studied the possibility of administering PAP intravenously.

Vihko's group has identified additional cellular functions for both isoforms of PAP. "I expect PAP has many different and important functions," she said. "This regulation of pain is not the only one-and not all of its functions are related to the production of adenosine."

The results of these studies will be reported in several forthcoming publications, Vihko said.

The findings reported in Neuron were patented by Vihko and the University of North Carolina in 2007. Until January of this year, Finnish law allowed an inventor to hold a patent without having to share those rights with her institution.

Said Zylka: "We are definitely looking for investors."

Haas, M.J. SciBX 1(38); doi:10.1038/scibx.2008.915

Published online Oct. 23, 2008

\section{REFERENCES}

1. Zylka, M. et al. Neuron; published online Oct. 8, 2008; doi:10.1016/j.neuron.2008.08.024

Contact: Pirkko Vihko, University of Helsinki, Helsinki, Finland e-mail: pirkko.vihko@helsinki.fi

Contact: Mark J. Zylka, University of North Carolina at Chapel Hill, Chapel Hill, N.C.

e-mail: zylka@med.unc.edu

2. Quintero, I. et al. Cancer Res. 67, 6549-6554 (2007)

3. Vihko, P. et al. Proc. Natl. Acad. Sci. USA 90, 799-803 (1993)

4. Knyihár, E. Experientia 27, 1205-1207 (1971)

\section{COMPANIES AND INSTITUTIONS MENTIONED}

Albert Szent-Györgyi University Medical School, Szeged, Hungary

BioLineRx Ltd. (Tel Aviv:BLRX), Jerusalem, Israel

Dendreon Corp. (NASDAQ:DNDN), Seattle, Wash.

Elan Corp. plc (NYSE:ELN), Dublin, Ireland

University of Helsinki, Helsinki, Finland

University of North Carolina at Chapel Hill, Chapel Hill, N.C.

University of Oulu, Oulu, Finland 